\title{
Assessment of Nutritional Status of Children Attending Paediatrics OPD of a Tertiary Care Hospital in Eastern Nepal
}

\author{
Thakur J', Bhatta NK ${ }^{2}$, Poudel P, Shah GS ${ }^{4}$, Singh RR
}

\begin{abstract}
Introduction: Malnutrition is one of the major health problem worldwide, especially in developing world and so is in Nepal, the causes being numerous. The objectives of this study were to assess the nutritional status of children attending paediatric OPD of BPKIHS and to find relation of the nutritional status with different factors. Material and Methods: This descriptive cross sectional study was done by face to face interviews using semi-structured questionnaire and anthropometric variables were recorded. Data of total 192 children was analysed by descriptive statistics. $p$-value $<0.05$ was considered significant. Results: According to IAP classification $50.52 \%$ were malnourished [grade I $65.97 \%$, grade II $26.8 \%$, grade III $7.21 \%$ ]. According to WHO classification $47.39 \%$ stuntedmoderate $89 \%$, severe $11 \%$ and $9.89 \%$ wasted [moderate $94.73 \%$, severe $5.26 \%$ ]. Female sex, low education level in mother, low economic status, unavailability of exclusive breast feeding, low birth spacing and hospitalization were significantly associated with malnutrition. Conclusion: Malnutrition is common in children visiting paediatric OPD of BPKIHS. Female sex, maternal illiteracy, poverty, early weaning, birth spacing and hospitalization in past were major risk factors for malnutrition.
\end{abstract}

Key words: Malnutrition, IAP, stunting, wasting, WHO

\section{Introduction}

$\mathrm{M}$ alnutrition is a major health problem worldwide especially in developing world. It is a major cause of morbidity and mortality in Nepal. The term malnutrition refers to both under nutrition as well as over nutrition. But here malnutrition refers to under nutrition. Various factors are implicated as the cause for malnutrition. Here we have tried to study the burden of malnutrition in children visiting paediatrics OPD of BPKIHS as it could be an indirect indicator of nutritional status of children in Eastern Nepal as BPKIHS is the main tertiary health care centre in this region. Further we have tried to see the association of various factors with malnutrition. The indicators of malnutrition are Stunting, Wasting and Underweight ${ }^{1}$.

\section{Material and Methods}

This descriptive cross-sectional study was carried out from $25^{\text {th }}$
${ }^{1} \mathrm{Dr}$ Jitendra Thakur, MBBS. MD Senior Resident. ${ }^{2} \mathrm{Dr}$ Nisha Keshary Bhatta, MBBS. MD. Professor. ${ }^{3}$ Dr Prakash Poudel, MBBS. MD. Additional Professor. ${ }^{4} \mathrm{Dr}$ Gauri Shankar Shah, MBBS. MD. Professor. ${ }^{5} \mathrm{Dr}$ Rupa Rajbhandari Singh, MBBS. MD. Professor and Head. All from the Department of Paediatrics, BP Koirala Institute of Health Sciences, Dharan, Sunsari, Nepal.

\section{Address for correspondence \\ Dr. Jitendra Thakur, Senior Resident \\ Department of Paediatrics \\ BPKHIS, Dharan-18, Sunsari, Nepal \\ Tel No; +9779804019499 \\ E-mail: Jthakur797@gmail.com}

\section{Acknowledgements: None \\ Funding: Nil \\ Conflict of Interest: None \\ Permission from IRB: Yes}

\section{How to cite}

Thakur J, Bhatta NK, Poudel P, Shah GS, Singh RR. Assessment of Nutritional Status of Children Attending Paediatrics OPD of a Tertiary Care Hospital in Eastern Nepal. J Nepal Paediatr Soc 2017;37(3):209-212.

doi:http://dx.doi.org/10.3126/jnps.v37i3.18701

This work is licensed under a Creative Commons Attribution 3.0 License.

\section{(c) (i)}


June to $23^{\text {rd }}$ July, 2010 for a duration of one month in paediatric OPD of BPKIHS with the objective to assess the nutritional status of children attending paediatrics OPD of BPKIHS and to find the risk factors associated with malnutrition. All children between 1 to 5 years visiting paediatrics OPD with mother and parents giving assent were included in the study. Face to face interviews were conducted using semi structured questionnaire after properly explaining the questionnaire.

Anthropometry (weight, height, length) was taken using standard methods and appropriate instruments. Weight was recorded with weighing Secca scale with an accuracy of $50 \mathrm{~g}$ and crown to heel length in 1-2 years with infantometer and height using stadiometer in 2-5 years age group, with an accuracy of $0.1 \mathrm{~cm}$. Oedema was diagnosed when there was bilateral pitting when pressure was applied above the medial malleolus for 30 seconds. Underweight was classified using Indian Academy of Pediatrics (IAP), stunting and wasting was classified according to World Health Organization (WHO). Data were analysed with Statistical Package for Social Sciences (SPSS) version 10 and p-value $<0.05$ was considered significant. Underweight was compared with sex, maternal education, economic status, breast feeding, and use of iron, folic acid and tetanus toxoid (TT) in mother during pregnancy, hospitalization of child, birth spacing, and colostrum feeding and hospital delivery.
Parameters were arbitrarily classified, maternal education: above and below SLC; monthly family income: $<8,000,8,000-16,000$ and <16,000; breast feeding: exclusive up to 6 months, mixed feeding and no breast feeding; birth spacing: $<3$ years and $>3$ years and were analysed using bivariate analysis.

\section{Results}

A total of 192 children were interviewed out of which 110 were male and 82 were females out of all; 97, 91 and 19 were underweight, stunted and wasted respectively.

\section{Discussion}

According to NDHS 2016, the prevalence of wasting in Nepal is $10 \%$ which is comparable to our study. The prevalence of stunting and under nutrition was higher in our study compared to national data ${ }^{3}$. The reason behind this could be a hospital based study. The factors they assessed which had high proportion of malnutrition were low birth weight, under nourishment in mother, maternal illiteracy, low family income and food insecurity. But the prevalence of stunting, wasting and under nutrition in study in Allahabad, India in 2006 was $51.6 \%, 10.6 \%$ and $36.4 \%$ which was similar to our study ${ }^{4}$.

Different Classifications of Malnutrition

Table 1: Indian Academy of Pediatrics [IAP] classification for underweight ${ }^{1}$

\begin{tabular}{cc}
\hline Grade of malnutrition & Weight for age of the standard [median]\% \\
\hline Normal & $>80$ \\
\hline Grade 1 & $71-80$ \\
\hline Grade 2 & $61-70$ \\
\hline Grade 3 & $51-60$ \\
\hline Grade 4 & $<50$ \\
\hline
\end{tabular}

Table 2: WHO Classification for malnutrition ${ }^{2}$

\begin{tabular}{ccc}
\hline & Moderate malnutrition & Severe malnutrition \\
\hline Symmetrical edema & No & Yes \\
\hline Weight for height & SD score $[-2$ to -3$]$ & SD score $<-3$ \\
\hline Height for age & SD score $[-2$ to -3$]$ & SD score $<-3$ \\
\hline
\end{tabular}

Table 3: Distribution of various aspects of malnutrition

\begin{tabular}{cccccc}
\hline Underweight & $\begin{array}{c}\text { Total } \\
\mathbf{9 7}(\mathbf{5 0 . 5 \% )}\end{array}$ & Stunting & $\begin{array}{c}\text { Total } \\
\mathbf{9 1 ( 4 7 . 3 9 \% )}\end{array}$ & Wasting & $\begin{array}{c}\text { Total } \\
\mathbf{1 9}(\mathbf{9 . 8 9} \%)\end{array}$ \\
\hline Grade 1 & $64(65.9 \%)$ & Moderate & $81(89 \%)$ & Moderate & $18(94.7 \%)$ \\
Grade 2 & $26(26.8 \%)$ & & & Severe & $1(5.26 \%)$ \\
\hline Grade 3 & $7(7.2 \%)$ & Severe & $10(11 \%)$ & & \\
\hline Grade 4 & 0 & & & &
\end{tabular}


Table 4: Factors affecting malnutrition

\begin{tabular}{|c|c|c|c|c|}
\hline Factors & Division & Total & Underweight & p-value \\
\hline \multirow{2}{*}{ Sex } & Male & 110 & 47 & \multirow{2}{*}{$<0.02$} \\
\hline & Female & 82 & 50 & \\
\hline \multirow{2}{*}{ Education level } & $<$ SLC & 129 & 73 & \multirow{2}{*}{$<0.02$} \\
\hline & $>$ SLC & 63 & 24 & \\
\hline \multirow{3}{*}{ Economic status } & NRs $<8,000$ & 32 & 21 & \multirow{3}{*}{$<0.02$} \\
\hline & NRs $8-16,000$ & 119 & 65 & \\
\hline & NRs $>16,000$ & 41 & 11 & \\
\hline \multirow{2}{*}{ Birth spacing } & $<3$ years & 81 & 54 & \multirow{2}{*}{$<0.001$} \\
\hline & $>3$ years & 111 & 43 & \\
\hline \multirow{3}{*}{ Maternal Breast Feeding } & Exclusive & 108 & 40 & \multirow{3}{*}{$<0.05$} \\
\hline & Mixed & 72 & 48 & \\
\hline & None & 12 & 9 & \\
\hline \multirow{2}{*}{ Hospitalization } & Yes & 21 & 15 & \multirow{2}{*}{$<0.05$} \\
\hline & No & 171 & 82 & \\
\hline \multirow{2}{*}{ Colostrum feeding } & Yes & 163 & 80 & \multirow{2}{*}{$>0.05$} \\
\hline & No & 29 & 17 & \\
\hline \multirow{2}{*}{ Iron and Folic acid in pregnancy } & Yes & 127 & 58 & \multirow{2}{*}{$>0.05$} \\
\hline & No & 65 & 39 & \\
\hline \multirow{2}{*}{ Tetanus Toxoid in pregnancy } & Yes & 135 & 66 & \multirow{2}{*}{$>0.05$} \\
\hline & No & 57 & 31 & \\
\hline \multirow{2}{*}{ Hospital delivery } & Yes & 149 & 74 & \multirow{2}{*}{$>0.05$} \\
\hline & No & 43 & 23 & \\
\hline
\end{tabular}

Similarly in same study by Bantamen $\mathrm{G}$ et. al. in northwest Ethiopia, factors that were found responsible for malnutrition were inappropriate child caring and feeding practices such as using unprotected source of water for drinking and frequency of diarrheal episode, child vaccination status, food handler or care giver poor hand washing practices, parental decision making on use money for child care ${ }^{5}$. In a study done by Sharma $\mathrm{KR}$ in Mugu district, Nepal, following factors were associated with malnutrition: food scarcity, poor hygiene and environmental practices, lack of care of the mother towards her child due to priority given to work and lack of knowledge about proper child feeding/care ${ }^{6}$.

In a study done by Md. Israt Rayhan and $\mathrm{M}$. Sekander Hayat Khan in Bangladesh $45 \%$ were stunted, $10.5 \%$ wasted and $48 \%$ under nutrition ${ }^{7}$. These studies were similar to our study. In the same study factors responsible for stunting were less birth spacing, small birth weight and maternal illiteracy; factors responsible for wasting were small birth weight and under nourished mother; factors for underweight were less birth spacing, small birth weight and under nourishment in mother.

In a study done by Ruwali D, prevalence of under nutrition, stunting and wasting was found to be respectively $22.7 \%, 37.3 \%$ and $25.7 \%$ and socioeconomic factor being the most important factor associated with malnutrition ${ }^{8}$. Similarly in a study done by Joshi H S, prevalence of stunting, wasting and under nutrition were respectively $13 \%, 12 \%$ and $26 \%$ and factors associated with malnutrition were determined to be maternal education status, socioeconomic status, occupation and dietary knowledge ${ }^{9}$. The difference in the result between our study and above two study is probably because of difference in population, geographical area and hospital based study.

Thus there is difference in prevalence of malnutrition in different parts of the world and there is difference within different parts of Nepal but the size remains remarkably alarming. Different study assessed different factors to assess the risk factors associated with malnutrition and common factors among them were family income, maternal education and birth weight.

\section{Conclusion}

Malnutrition still prevalent in children visiting paediatric OPD at BPKIHS and in the eastern part of Nepal. Factors responsible for underweight were female sex, low education level of mother, poor economic condition, less birth spacing, lack of exclusive maternal breast feeding and previous hospitalization. Thus these parameters should be taken care of to deviate the curve of malnutrition. 


\section{References}

1. Paul VK, Lodha R, Agarwala A. Nutrition. In: Paul VK Bagga A, Sinha A. Ghai Essential Pediatrics $8^{\text {th }}$ ed. New Delhi: CBS Publishers and Distributors; 2013. p. 97.

2. D Shah, Gupta P. Nutrition and Health. In: Gupta P. Textbook of Pediatrics. New Delhi: CBS Publishers and Distributors; 2013. p. 58.

3. Ministry of health, Nepal Demographic and Health Survey,2016

4. Dinesh Kumar, N.K. Goel, Poonam C. Mittal and Purnima Misra. Influence of Infant-feeding Practices on Nutritional Status of Under-five Children. Indian J Pediatr 2006;73(5):417-21.

5. Bantamen G, Belaynew W, Dube J. Assessment of Factors Associated with Malnutrition among Under
Five Years Age Children at Machakel Woreda, Northwest Ethiopia: A Case Control Study. J Nutr Food Sci 2014:4: 256. DOI: 10.4172/2155-9600.1000256

6. Sharma KR. Malnutrition in Children Aged 6-59 Months in Mugu District. J Nepal Health Res Counc 2012;10(20):156-9.

7. Md. Israt Rayhan and M. Sekander Hayat. Factors causing malnutrition among under five children in Bangladesh. Pak J Nutr 2006;5(6):558-62.

8. Ruwali D. Nutritional status of children under five years of age and factors associated in Padampur VDC, Chitwan. Health Prospect. 2012 Jun 1;10:14-8.

9. Joshi $\mathrm{H} \mathrm{S}$ et al. Determinants of Nutritional Status of School children-A Cross Sectional Study in the Western Region of Nepal. NJIRM 2011;2(1):10-5. 